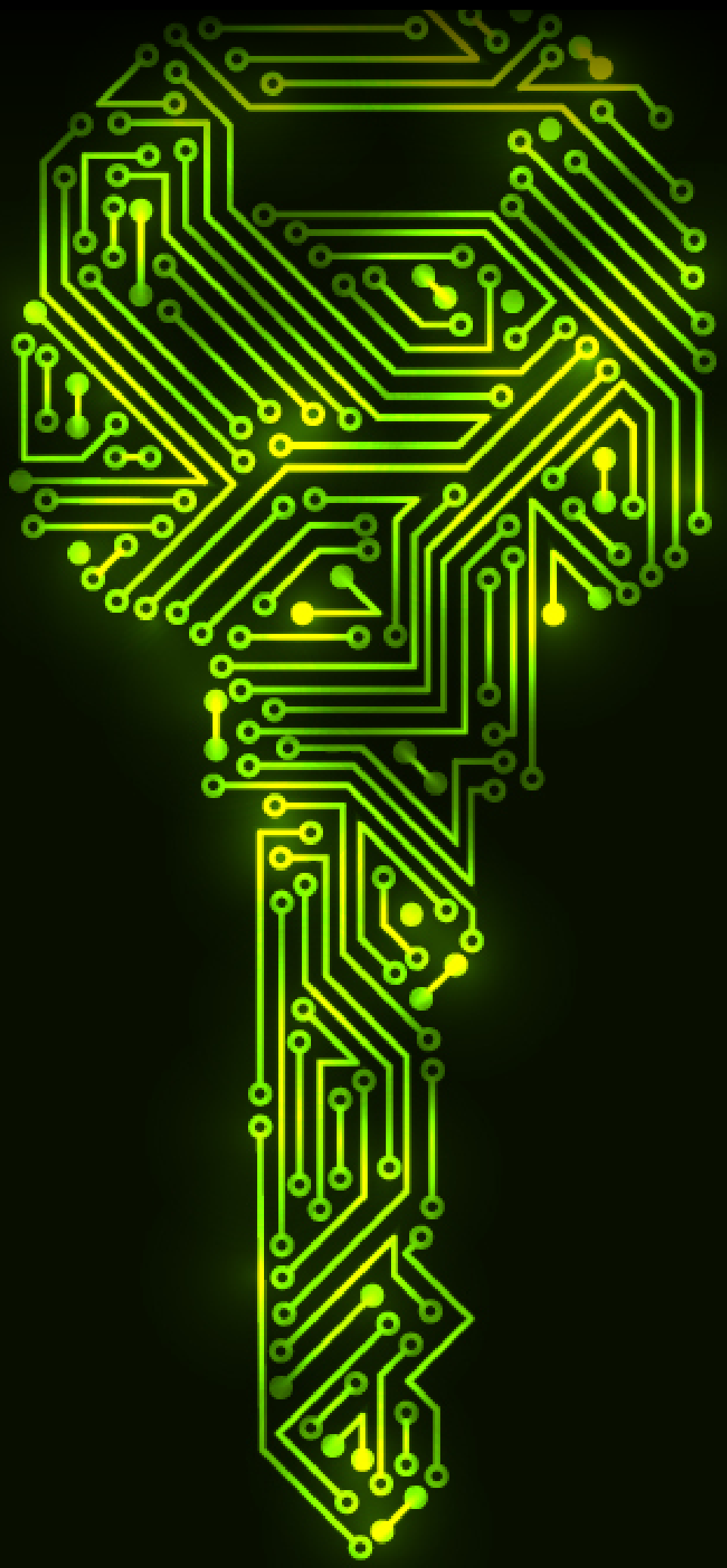




\section{NO RASTRO DO BLOCKCHAIN}

\section{Crescem as criptossoluções no Brasil, mas ainda é preciso superar o desconhecimento da população e as incertezas regulatórias.}

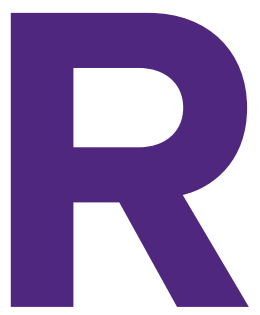

ecentemente uma criança nos perguntou: "o que é blockchain?". Esboçamos explanar sobre os diversos elementos relacionados a essa tecnologia, como hashes critptográficos, protocolos de consenso, ledger distribuído, criptomoedas e tokens, mas logo percebemos que não conseguiríamos responder-lhe com uma abordagem técnica. Seria preciso explicar uma das mais importantes criações tecnológicas das últimas décadas sem falar em tecnologia "É uma forma diferente e criativa de guardar informações", sintetizamos.

"Sabe quando você escreve coisas no seu caderno para não esquecer? É a mesma ideia, mas, em vez de um único caderno, há milhões de cadernos, todos iguais, espalhados mundo afora". Eis que a criança acrescentou de forma brilhante: "isso me parece uma boa ideia, pois assim nunca perderei o que escrevi! Mas precisa garantir que as cópias sejam iguais, para não dar confusão".

Em instantes, ela foi capaz de resumir, mesmo que superficialmente, a inspiração de Satoshi Nakamoto quando, em 2008, inventou o bitcoin e a própria tecnologia blockchain . A criptomoeda buscava recriar, no ambiente digital, a experiência de uso do dinheiro, garantindo privacidade, aceitabilidade e confiança nas transações remotas.

\section{ORIGENS E APLICAÇÕES}

A busca por criar dinheiro eletrônico remonta à década de 1990, nos primórdios da internet, quando especialistas - hoje denominados de cypherpunks - tentaram emular as características do dinheiro físico no ambiente digital, sem a intermediação de instituições bancárias ou financeiras. Muitas iniciativas emergiram, mas todas fracassaram por não conseguirem garantir a integridade do sistema. Sem uma espécie de cartório digital registrando e chancelando todas as transações, fraudes poderiam ocorrer - e de fato ocorreram -, minando a construção de confiança dos usuários.

Mais de uma década depois, a solução veio de forma simples e elegante: em vez de um único fiel depositário da verdade, todos os participantes da rede teriam uma cópia, sempre atualizada, das informações geradas na rede. Em outras palavras, aquele caderno de registros seria agora compartilhado com milhões de pessoas, de modo automático e com assinaturas digitais atestando seu teor. Metaforicamente, as páginas afixadas no caderno seriam como blocos de informações encadeados com recursos criptográficos, ou seja, block+chain.

Estava solucionada uma importante questão para os negócios no mundo digital, com a criação da primeira criptomoeda. Parodiando o lema estadunidense grafado nas notas de dólar, entusiastas do bitcoin chegaram a cunhar a expressão "in cryptography we trust". A solução era tão criativa 


\section{APLICAÇÕES DA TECNOLOGIA BLOCKCHAIN}

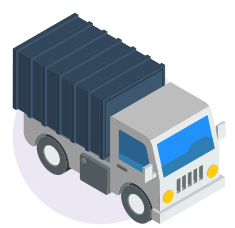

Logística: a Intellipost utiliza blockchain para gerenciamento de frete no Brasil, integrando empresas de e-commerce, varejistas, atacadistas e indústrias com transportadoras, proporcionando visão holística das entregas.

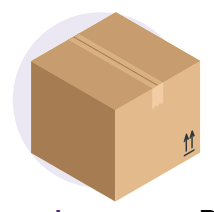

Cadeia de suprimentos: a Plataforma Verde (GreenPlat) utiliza blockchain para rastrear toda a cadeia produtiva de suprimentos e comercial, além de gerenciar as perdas produtivas.

Saúde: o Blockchain no SUS é um projeto do Ministério da Saúde para armazenar e integrar informações de saúde dos cidadãos. Está sendo utilizado para contabilizar informações dos resultados de exames de Covid-19.

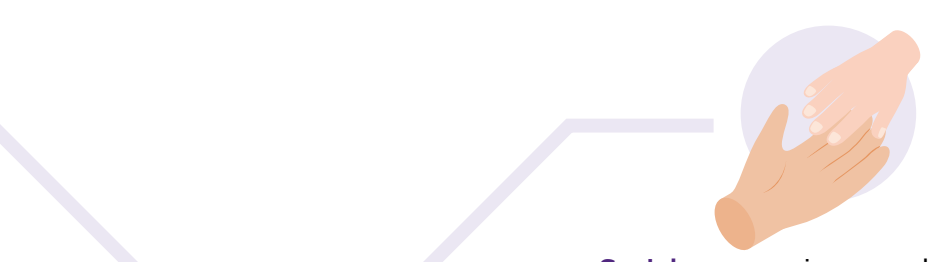

Social: para apoiar o combate à Covid-19 com rastreamento, a Blockforce desenvolveu o Desviralize, uma plataforma de contact-tracing.

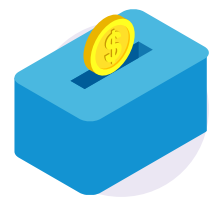

Financeiro: a Remessa Online utiliza a blockchain da ripplenet para se conectar a provedores de pagamento ao redor do mundo, ganhando agilidade, preços baixos e competitividade.

Moda: o Instituto C\&A e o Instituto Alinha desenvolveram a TAG Alinha para trazer transparência à cadeia produtiva no mundo da moda.
- e impecável - que logo foi empregada em outros contextos e para diversas finalidades, muito além das transações financeiras. A lista de aplicações é imensa e crescente (veja no quadro com exemplos do Brasil).

O grande feito da tecnologia blockchain em tais iniciativas é propiciar a confiança dos seus integrantes sem a necessidade de agentes intermediários, ao gravar de forma perene, inviolável e auditável as informações e transações dos participantes.

Além de proporcionar a confiabilidade e aperfeiçoar plataformas digitais, a tecnologia de blockchain também possibilita a emergência de novos modelos de negócio. Segundo pesquisa da Distrito em outubro de 2020, atuavam no país mais de 180 startups que oferecem criptossoluções, desde sistemas para gestão de resíduos industriais (Plataforma Verde) ou criptoativos para rastreamento de investimentos do setor público (BNDES Token), até uma plataforma para envio de dinheiro ao exterior (Remessa Online).

\section{OPORTUNIDADES E DESAFIOS}

Um exemplo de empresa que está apostando em blockchain é a OriginalMy, objeto de dissertação de Trícia Karla Lacerda Moraes no Mestrado Profissional em Gestão para Competividade (MPGC), na linha de Tecnologia de Informação, sob orientação de Adrian Kemmer Cernev. Fundada em 2015, a startup vem se destacando no cenário internacional, tendo recebido em 2020 o prêmio de solução digital mais inovadora pelo World Summit Awards (WSA). Percebendo o potencial das redes blockchain para solucionar necessidades cotidianas de indivíduos e organizações, a OriginalMy concebeu novos serviços de identificação e de propriedade intelectual, de forma a combater plágio e fraude documental e fornecer prova de identidade e reconhecimento de assinaturas digitais. Além disso, a empresa também chegou a interagir nas discussões sobre o aprimoramento das próximas eleições no Brasil, propondo uma solução totalmente online de forma criptografada e secreta. 
A proposta de valor da OriginalMy é simplificar e baratear as atividades de cartório, eternizando registros online, cuja verificação de autenticidade pode ser feita sem a necessidade de intermediários - inclusive dela mesma! Um dos serviços oferecidos pela empresa é o registro de documentos em redes blockchain. Diferentemente de um cartório tradicional, a OriginalMy não armazena o conteúdo original, registrando apenas sua assinatura digital, ou mais precisamente o respectivo hash criptográfico. Assim, além de garantir o registro de um documento, que pode ser atestado por qualquer indivíduo com acesso à rede, a empresa resguarda a privacidade e confidencialidade do conteúdo.

Entretanto, alguns desafios irromperam em sua jornada: atrair profissionais capacitados em blockchain, instruir clientes e demais stakeholders sobre a tecnologia emergente e, principalmente, superar restrições regulatórias. De fato, alguns serviços são reservados ao sistema cartorial oficial, como os registros civis de nascimento e falecimento e de transferência de bens imóveis e veículos. Por outro lado, na inexistência de regulamentação restritiva, pressupõe-se a permissibilidade do serviço.

Mas isso nem sempre acontece de modo espontâneo. Comumente, para que ocorra a ampla adoção de um serviço disruptivo, uma tradição de aceitabilidade precisa ser construída, inclusive nas instâncias do direito. Um registro em blockchain teria validade jurídica, mesmo sendo tecnicamente incontestável?

Em alguns casos, os reguladores, por não acompanharem as novas tecnologias, optam por proibir ou frear as inovações. A própria OriginalMy sofreu com o hiato regulatório no Brasil. Seu fundador recebeu uma carta oficial com sugestão velada de prisão, quando buscava realizar o primeiro initial coin offering (ICO) no país, método inovador de financiamento no mundo dos criptonegócios. Para superar a restrição, em poucas semanas a empresa se internacionalizou na Estônia, buscando a segurança regulatória existente nesse país, além do incentivo para o desenvolvimento de inovações relacionadas a blockchain. Outros países, tais como Suíça, Japão e Malta, também são expoentes e apoiadores do desenvolvimento e da disseminação da tecnologia blockchain no cenário global.

\section{INOVAÇÕES SOCIAIS E GOVERNAMENTAIS}

Soluções de tecnologia blockchain também vêm surgindo no Brasil para resolver questões sociais e governamentais. Um exemplo de destaque é o projeto blockchain no Sistema Único de Saúde (SUS), que visa melhorar o cenário atual, em que hospitais e laboratórios não compartilham dados e há um número crescente de fraudes envolvendo dados de pacientes. O projeto busca conectar todo o sistema de saúde nacional, distribuindo informações na rede, de forma rastreável e segura, propiciando amplo acesso de profissionais de saúde e pacientes a dados hospitalares e laboratoriais. Além disso, impulsionado pela necessidade de resolver o problema de subnotificação desde o início da pandemia, o blockchain no SUS teve seu primeiro case com a contabilização dos resultados dos exames de Covid-19.

Em relação à pandemia, vale menção a outra iniciativa, da startup Blockforce. A empresa desenvolveu e lançou o Desviralize, um serviço gratuito que utiliza contract-tracing em uma rede blockchain para viabilizar registros de casos de Covid-19 no país. Além desse projeto, ela também participou do desenvolvimento da Moeda Seeds, cujo objetivo é fornecer microfinanciamentos para empreendedoras de baixa renda. Por meio de redes cross-blockchain, de qualquer lugar do mundo, investimentos seguros e transparentes podem ser feitos em projetos selecionados por especialistas da Moeda, os quais promovem a valorização e o desenvolvimento das comunidades locais, sempre associados a pelo menos um dos Objetivos de Desenvolvimento Sustentável da Organização das Nações Unidas (ONU). Adicionalmente, a Moeda Seeds promoveu ainda o maior ICO da história do Brasil, sendo um dos mais avançados projetos baseados em blockchain do mundo.

\section{CONCLUSÃO}

Em resumo, nos últimos anos, diversas criptossoluções foram desenvolvidas e ofertadas ao mercado. Ao mesmo passo, muitas pessoas, organizações e governos passaram a adotá-las. Entretanto, para ampliar o valor para o ecossistema, faz-se necessário expandir ainda mais sua utilização, superando o desconhecimento da população e as incertezas regulatórias. Isso significa que mesmo a tecnologia mais poderosa e robusta existente para a construção de confiança digital precisa contar com a confiança prévia dos usuários para atingir escalabilidade.

\footnotetext{
PARA SABER MAIS:

Adrian Kemmer Cernev e Eduardo Henrique Diniz. Blockchain: a nova revolução tecnológica nos serviços. In: Paulo Bastos Tigre e Alessandro Maia Pinheiro (org.). Inovação em serviços na economia do compartilhamento, 2019

Trícia Karla Lacerda Moraes e Adrian Kemmer Cernev. OriginalMy: blockchain technology and business defying a 20th-century regulation. Journal of Information Technology Teaching Cases, v.10, n.2, 2020. Disponivel em: doi.org/10.1177\%2F2043886919899400 Don Tapscott e Alex Tapscott. Blockchain revolution: como a tecnologia por trás do bitcoin está mudando o dinheiro, os negócios e o mundo, 2017.
}

ADRIAN KEMMER CERNEV > Professor da FGV EAESP > adrian.cernev@fgv.br TRÍCIA KARLA LACERDA MORAES > Mestra e doutoranda em Administração de Empresas pela FGV EAESP > triciamoraes@gmail.com 